\title{
Neurotic Depression
}

National Cancer Institute

\section{Source}

National Cancer Institute. Neurotic Depression. NCI Thesaurus. Code C35369.

A term used for any state of depression that is not psychotic. 